\title{
Congratulatory address
}

Ushio Yano MD. PhD. ${ }^{1}$

${ }^{1}$ The Yano otolaryngology hospital

I was asked to submit the congratulatory address in publishing a memorial edition in order to apply the PubMed registration in USA.

The aging of a human being which he has foreseen is clear. Prof. Takizawa knew the inevitability of that and has continued the challenge to prevent the social disruption. Nobody would have expected that the endeavor of preventing the social disruption by the aging process of societies, which was named the Aging crisis, can be achieved by cooperation of doctors in the world.

This memorial edition can contribute to the improvement in the welfare of human beings greatly, and also I am sure that people who collaborate with him can prevent the Aging crisis.

Now, I write recollections to a congratulatory address.

Prof. Takizawa who is a chief editor of the BIOPHILIA journal and his daughter have been my patients.

It seemed that my soliloquy as "Why did he run as a candidate for a mayor? (Success in an election was not expectable)" was transmitted to him from her at the time of his defeated mayoral election. At the situation that she attended my hospital regularly, I got his letter. I remember that I was very much surprised at receiving his letter despite the twenty years that have elapsed from that time.

The letter was related the meaning of the election campaign as follows;

"Anxiety to an aged society arriving" and "It is possible to remove the anxiety since elderly people independence can be attained by the rehabilitation medicine innovation. And the campaign should enable the innovation as a seed.",

"It can be predicted that laboriousness and the length in order to reach the purpose." and "There is a necessity to deal with it from the viewpoint of philanthropy without fearing a result although it is very difficult for him to return to "politician." and

"As a conclusion, he explained that he had committed himself to live with a social contribution in his school days."

Although there wasn't any doctor in the study group till then, it was a weakness of an implementation of the study. I heard that doctors who had looked at this election participated in the study. It seems that his challenge which doesn't fear his failure result induced the supposition result.

It was my pleasure to know the progress of studies by the report of the Japan wire agency "Jiji Press" that were offered by him from time to time after that.

I send sincere praise to the members of the research team of medicine, engineering, and social science which cooperated closely like the "family" who consists of a volunteer with him in the world, and expect progress of the future research from now on. 